\title{
ENTRE A TEORIA E A PRÁTICA: OS PROFESSORES NAS ESCOLAS PÚBLICAS PAULISTAS E SEUS DESAFIOS NO SÉCULO XXI
}

\author{
Diana da Cruz Fagundes Bueno ${ }^{1}$ \\ José Roberto Nunes de Azevedo²
}

Resumo: Buscamos evidenciar as contradições existentes entre o aumento da escolarização e a qualidade do ensino, bem como, os percalços pelos quais os profissionais da educação deparam-se ao longo da carreira. Observa-se a necessidade de uma educação não excludente, integradora e que valorize as experiências dos alunos, rompendo desta forma com um ensino meramente vinculado ao âmbito do mercado de trabalho, possibilitando à clientela escolar o direito à cidadania e à construção do conhecimento autônomo.

Palavras-chave: Formação de professores; Educação; Escola.

\section{THEORY AND PRACTICE BETWEEN: TEACHERS IN PUBLIC SCHOOLS PAULISTAS AND ITS CHALLENGES IN THE TWENTY-FIRST CENTURY}

\begin{abstract}
We seek to highlight contradictions between increased schooling and quality of education, as well as mishaps in which education professionals are faced throughout their career. The need of a non-exclusionary education, integrative and that values the experiences of students breaking this way with a purely linked

\footnotetext{
1 Professora do Núcleo de Educação à Distância da Universidade de Taubaté (Nead/Unitau) e Professora Efetiva da Secretaria da Educação do Estado de São Paulo; Doutoranda do Programa de Pós-graduação em Geografia da FCT/Unesp, Campos de Presidente Prudente-SP; Pesquisadora vinculada ao Grupo de Pesquisa em Gestão Ambiental e Dinâmica Sócioespacial (GADIS/Unesp). Email: dianafag@yahoo.com.br.

${ }^{2}$ Professor Efetivo da Secretaria da Educação do Estado de São Paulo; Doutor em Geografia pela FCT/Unesp; Pesquisador do Centro de Estudos de Geografia do Trabalho (CEGeT/Unesp); Editor da Revista Cosmos - ISSN:1670-0650. E-mail: joserobertocosmos@yahoo.com.br.
} 
education to the scope of the labor market is observed, enabling the school clientele the right to citizenship and the building of self-knowledge.

Keywords: Teacher training; Education; School.

\section{ENTRE TEORÍA Y PRÁCTICA: MAESTROS EN ESCUELAS PÚBLICAS PAULISTAS Y SUS RETOS EN EL SIGLO XXI}

Resumen: Buscamos resaltar contradicciones entre el aumento de la escolaridad y la calidad de la educación, así como los accidentes en los que profesionales de la educación se enfrentan a lo largo de su carrera. Se observa la necesidad de una educación no-exclusiva, integrador y que valore las experiencias de los alumnos rompiendo de esta manera con una mera teaching vinculados al ámbito del mercado de trabajo, lo que permite la escuela clientela el derecho de la ciudadanía y la construcción de auto-conocimiento.

Palabras clave: La formación del profesorado; Educación; School.

No final dos anos de 1980 e início dos anos 1990, o movimento dos educadores em defesa da escola pública, sindicatos e associações de professores não só discutiam como também exerciam uma postura ativa, exigindo que o projeto político-pedagógico da escola constituísse o centro das discussões.

Conforme nos esclarece Romanelli (1980), historicamente, observou-se no Brasil uma incapacidade das camadas dominantes em reorganizarem o sistema educacional de forma que se atendesse harmonicamente tanto a demanda social de educação quanto às novas necessidades de formação de recursos humanos exigidos pela economia em transformação.

Especialmente na virada do século $X X$ percebe-se a concepção de formação do professor enquanto um: "[...] intelectual crítico, um profissional reflexivo e pesquisador e elaborador de conhecimentos" (LIBÂNEO: 2004, p.78). 
Nidelcoff (1983) questiona em seu livro o papel da escola no âmbito da estrutura social tendo em vista que esta entidade que recebeu por muito tempo a tarefa de garantir ao conjunto das pessoas condições igualitárias em um ambiente menos desigual não tem atingido seus reais objetivos, sendo necessários, portanto, repensar as funções a que são atribuídas. Ambiente esse que deve estar em sintonia com as atividades e situações propostas e que revele e amplie o interesse e a esfera de conhecimento das crianças envolvidas. Neste cenário possibilita-se a exploração e a descoberta aliadas a construção de noções que no caso particular, por exemplo, do ensino infantil relaciona-se ao conhecimento do mundo físico e social incluindo não apenas as ciências sociais e da natureza, a língua e a matemática denominados por Kramer (1995) como eixos básicos da função pedagógica na pré-escola. Como bem retrata Gomes (1993, p.127) devemos ter em consideração especialmente no caso da formação da educação básica e particularmente do ensino infantil que:

\footnotetext{
A escola precisa ser um espaço de acesso a todas as linguagens (escrita, musical, corporal, plástica, dramática etc.) mas não necessariamente um espaço de formação de atores, escritores, gravadores, músicos etc. Ela é um espaço de experiências totalizadoras onde a criança poderia ampliar seus referenciais de mundo. (GOMES, 1993, p.127).
}

A dita formação esbarra, no entanto, em um contexto marcadamente capitalista em que predomina uma preparação propedêutica que raramente preocupa-se com o individuo e sua formação para o mundo, mascara por vezes elementos importantes da experiência e valoriza enormemente o campo voltado ao trabalho.

Do mesmo modo faz-se necessário pensar a respeito do papel da produção da Ciência no contexto político, haja vista que o conjunto de saberes difundidos nos ambientes escolares passa por um longo processo de desenvolvimento e reflexão anteriores aos bancos escolares, formulando verdades e teorias.

Tão logo compreendermos as faces das políticas educacionais na formação de professores é situação essencial e isto obriga-nos necessariamente a recorrer às bases em que se estruturam enquanto modelo de desenvolvimento escolhido para o país. 
Nesse quesito devemos esclarecer que a educação formal ancora-se fundamentalmente nos professores, os quais são tidos como agentes de mudança na medida em que atribui-se aos mesmos, papel determinante na formação do caráter e espírito das novas gerações, de tal forma que os ajude simultaneamente a encontrar, organizar e gerir o saber ${ }^{3}$, tão logo faz-se importante aos mesmos a devida valorização profissional associada a motivação e interesse pela prática docente.

Tal aspecto é importante na medida em que percebemos ser relativamente comum encontrar professores desestimulados reclamando sobre as dificuldades, como "alunos que não querem nada", sobrecarga, falta de condições de trabalho, enfim, são diversos os fatores que levam esses profissionais a se sentirem desestimulados.

Como bem salienta UNESCO (1999, p.159): "Nunca é demasiado insistir na importância da qualidade do ensino e, portanto, dos professores" e nesta acepção considerar que: "[...] melhorar a qualidade e a motivação dos professores deve, pois, ser uma prioridade em todos os países".

Concordamos com Libâneo (2004), que retrata a desvalorização social da figura do professor. Segundo o referido autor tal desvalorização da profissão do professor prejudica a construção da própria identidade dos futuros professores, aspecto este que percebemos nos diálogos e reuniões no ambiente escolar na qual observamos não raramente a frustação em relação aos rumos tomados a escola e as perspectivas, sobretudo dos professores mais jovens.

Por sinal, tais elementos são imprescindíveis para se entender a lógica no qual se abarca o trabalho escolar e que está vinculada a diretrizes nacionais, estaduais e municipais de ensino e também porque é necessário saber que concepções de homem e sociedade caracterizam os documentos oficiais, uma vez que expressam os interesses dominantes de quem controlam os órgãos públicos.

De fato, a Universidade deve cumprir seu papel de produção do conhecimento o qual pela sua própria natureza necessita ser irrestrito, isto é, não ficar apenas nas mediações acadêmicas, mas atingir o conjunto da sociedade na medida em que é esta sua verdadeira mantenedora.

\footnotetext{
${ }^{3}$ Para mais informações sobre esse aspecto ver: Barbosa e Azevedo (2004).
} 
Ao mesmo tempo como bem atesta Linhares (1991) devemos enfrentar com coragem o verdadeiro fosso existente entre a escola vista apenas como lugar de transmissão do conhecimento e apartada da formação contínua e as Universidades e por extensão a prática da pesquisa.

Portanto, o desafio posto é superar a dicotomia escola-pesquisa uma vez que ao contrário do que se figura não são polos divergentes, mas, ao contrário, complementares.

A esse respeito é interessante observar as reflexões de Linhares (1991) a qual aponta que o fracionamento da categoria do magistério funciona negativamente para os professores, seja na dimensão técnica e pedagógica como também no âmbito sindical e político, uma vez que tende a hierarquizar os níveis do saber de tal forma a desprestigiar o trabalho e o merecimento daqueles que se dedicam apenas à educação básica.

Neste ínterim conforme nos alerta Pretto (1996), em sua reflexão sobre "Uma escola sem/com futuro", é importante que ocorra uma verdadeira revisão na formação de professores e inclusive no papel das universidades públicas dado que estas são as principais responsáveis pela transmissão do conhecimento e, portanto, são os responsáveis por trabalhar tais recursos, o que, aliás, não se configura como uma tarefa fácil, haja vista a condição em que se apresenta a escola atual.

O mesmo pode se dizer quanto aos valores e idéias proclamados na legislação escolar.

Nesse cenário observamos que a política educacional, sobretudo do governo $\mathrm{FHC}$ foi elaborada através de gabinetes e, portanto nunca atenderam as demandas sociais. Priorizam o mercado de trabalho, reduzindo a educação dentro de uma visão economicista da política neoliberal. Priorizam a formação de mão-deobra flexível para o mercado flexível.

Tão logo nesse contexto de globalização algumas reformas constitucionais foram encaminhadas: administrativa, previdenciária, educacional; foram criados o FUNDEF, a Lei 9131 (provão), o Decreto 1108/1997 e a Portaria 476/1998 que modificaram o ensino técnico, os PCN's e as Diretrizes Curriculares para o Ensino Superior, o SAEB (Educação básica) e SAEM (Ensino Médio), sistemas de avaliação. 
O artigo 62 da LDB, através do Decreto 3276/1999 acaba com a formação de professores para educação infantil e para as classes iniciais ( $1^{\circ}$ a $4^{\circ}$ série) nos cursos de licenciatura plana em Pedagogia.

Como nos aponta Oliveira (2004, p.1144/45):

[...] a educação como principal meio de distribuição de renda e garantia de mobilidade social será combinada à noção de que o acesso, hoje, à cultura escrita, letrada e informatizada é inevitável e constitui-se no único meio de ingressar ou permanecer no mercado de trabalho. (OLIVEIRA, 2004, p. 1144/45).

Entretanto, na realidade as salas de aula diferem muito daquela pensada e proposta pelo Estado na medida em que se trata de uma clientela diversificada com interesses múltiplos e "formada" para fins sociais diferenciados.

De maneira geral, vê-se que existe uma desigualdade de oportunidades entre as crianças de classe média-alta e das populares, sendo estas últimas marginalizadas no processo escolar, uma vez que sua bagagem não é aquela esperada e exigida pela educação formal ${ }^{4}$.

Não é demais lembrar, amparados em Linhares (1991), que a questão do magistério não deve ser pensada isoladamente e sim, associada a outros aspectos essenciais como a própria crise da escola e da universidade que é fruto das matrizes técnicas implantadas pelo próprio sistema econômico capitalista vigente e que impedem a unidade do trabalho pedagógico pela sociedade.

Ao adentrarmos em uma esfera de maior complexidade podemos perceber que, existem alguns entraves para o desenvolvimento de um trabalho de qualidade, dificultando na prática da equipe à dinâmica geral do ensino: sobrecarga de trabalho dos educadores, preocupados com a sobrevivência, em função dos parcos salários; falta de tempo para estudar, planejar as aulas, pesquisar e buscar mudanças.

Assim o professor precisa avaliar a pertinência dos objetivos e conteúdos propostos pelo sistema oficial, verificando em que medida atende exigências de

\footnotetext{
${ }^{4}$ É no mínimo intrigante notarmos nos "Parâmetros Curriculares Nacionais" a verticalidade que assumem os objetivos pelos quais os alunos(as) do ensino fundamental devem conquistar: Cidadania, diálogo, pluralidade, perceber-se integrante, conhecimento ajustado, conhecer o próprio corpo, diferentes linguagens, etc., bem como seus temas transversais: Ética, pluralidade cultural, orientação sexual, meio ambiente, saúde, trabalho e consumo. Destaca-se particularmente a última articulação e seus significados na sociedade vigente.
} 
democratização política e social, expectativas da clientela escolar. Ou seja, como revela Kramer (1995) faz-se necessário coerência entre pressupostos teóricos e sua implementação na realidade, uma vez que tal instrumento em primeira instância é justamente $\mathrm{o}$ apoio à prática e aos caminhos a percorrer pelo docente.

Callai (2001), alude à importância, por exemplo, da Geografia como componente curricular da educação básica capaz de promover a cidadania, competindo a esse desígnio o rompimento com a "mesmice da escola", marcada entre outras pela demarcação oficial dos conteúdos, distantes da realidade do alunado.

Os conteúdos escolares estão em contradições tanto pelas possibilidades reais dos alunos em assimilá-los quanto aos interesses da sociedade dominante, na medida em que podem ser usados para disseminar a ideologia de grupos e classes minoritárias.

Se a educação escolar deve exercer a sua contribuição das lutas pela transformação da sociedade, os conteúdos sistematizados visam instrumentalizar as crianças e jovens das camadas populares para a sua participação ativa no campo econômico, social, político e cultural. Basicamente, definirá que conteúdos são importantes ou não.

A escolha dos conteúdos deve satisfazer as seguintes preocupações: como ligar a exigência do domínio dos conhecimentos com a vida real das crianças? Que conhecimentos introduzidos a exigências teóricas e práticas do contexto social não fazem parte da experiência cotidiana das crianças?

O domínio efetivo dos conhecimentos não se garante, pois, apenas pela memorização e repetição de fórmulas e regras. A compreensão teórica e prática, os conhecimentos e habilidades obtidos nas próprias aulas precisam ser utilizados nas situações concretas postas pela vida prática. É preciso não confundir "conhecimentos relevantes para a prática social" e "conhecimento prático".

Professores entendem que ligar os conhecimentos com a realidade é ensinar apenas coisas práticas. Visão muito estreita do critério de relevância social. Os conhecimentos são relevantes para a vida concreta quando amplia o conhecimento da realidade. Os alunos devem passar a raciocinar, a desenvolver a capacidade de abstração, enfim, a pensar a própria prática. 
Assim, o nível das coisas simplesmente práticas passam a alcançar um nível de experiência e pensamento com o conhecimento científico e teórico. Agir praticamente significa utilizar o poder intelectual frente às tarefas da vida, seja na escola, seja na sociedade.

Outra questão que deve ser colocada nesse momento diz respeito à dificuldade, em todos os níveis de ensino, e em particular no ensino primário, da fragmentação do conhecimento e da forma como isto é desenvolvido pelos professores.

Inúmeras escolas através de sua grade curricular e por meio da divisão dos conteúdos ou mesmo das atividades no decorrer das aulas acabam enfatizando a fragmentação do saber. A divisão se dá, e não raras vezes. A oposição entre saberes são vinculados como se fosse mais fácil compreender a realidade pelas partes e não enfocando uma visão de conjunto das relações trabalhadas pela sala ou classe.

O professor deve conhecer os objetivos estabelecidos no âmbito do sistema escolar oficial, seja no que se refere a valores e ideais educativos, seja quanto às prescrições de organização curricular e programas básicos das matérias.

Por sinal, vale ressaltar, a título de exemplo, conforme temos percebido, através, especialmente do trabalho docente, que podemos verificar diversos pontos negativos e positivos que caracterizam o currículo atual na Rede Pública de Ensino do estado de São Paulo, sendo os mais comuns entre as matérias oficiais:

Negativos: a) Não considera o desenvolvimento cognitivo dos alunos; b) Possui dificuldade de adequação do conteúdo à realidade espacial da clientela, sendo que em alguns casos está dirigido especialmente à realidade de estudantes provenientes das grandes cidades do país; c) O currículo engessa a ação docente na medida em que este precisa cumprir uma série de conteúdos em um período restrito, não sendo possível identificar todas as habilidades necessárias pela turma; d) O enfoque interdisciplinar não está claro em determinados assuntos vinculados pelo material distribuído pela Secretaria da Educação.

Positivos: a) O currículo está unificado e os professores e estudantes possuem uma uniformidade em relação ao que ensinar e o que aprender, respectivamente, independente da região do estado em que estiver morando; b) Melhor organização do trabalho a ser desenvolvido pelos professores e 
planejamento dos conteúdos pela utilização de material disponibilizado o qual complementa e auxilia as atividades propostas pelo professor; c) O currículo atual possibilita envolvimento maior entre os alunos haja vista a quantidade de atividades disponíveis incluindo a análise de textos e figuras, produção de textos, exercícios e dicas de pesquisa sobre cada componente curricular; d) Enfoque prático do assunto e agilidade maior nas aulas, conforme diversidade de situações de aprendizagem e disponibilidade de opções teóricas e metodológicas de abordar cada conteúdo previsto.

Esse conhecimento se faz necessário porque o trabalho escolar esta vinculado a diretrizes nacionais, estaduais e municipais de ensino e também porque é necessário saber que concepções de homem e sociedade caracterizam os documentos oficiais, uma vez que expressam os interesses dominantes de quem controla os órgãos públicos.

Todas essas questões nos levam a pensar e repensar a escola: como a mesma age em relação à sociedade atual; os desafios que terá de alçar na atual conjuntura; e quais objetivos que pretende alcançar.

Assim, conforme destaca Vieira (2005, p.14) é preciso ter em mente que a escola sozinha, isolada, não consegue desenvolver uma proposta educativa mais ampla que responda satisfatoriamente às novas demandas. Entretanto isso somente poderá ser atingido quando existir uma proposta de ação comum que dê significado e direção ás atividades individuais dos agentes envolvidos.

Cavalcanti (1998, p.11), contribui em relação à sugestiva interface existente entre Geografia-escola-construção de conhecimentos. Logo, a mesma reitera a importância desse saber e neste aspecto aponta que: "[...] o conhecimento geográfico é, pois, indispensável à formação de indivíduos participantes da vida social à medida que propicia o entendimento do espaço geográfico e do papel desse espaço nas práticas sociais".

Por sinal, do ponto de vista da pré-escola, por exemplo, verificamos a partir das reflexões de Esteban (1993), que é possível analisar e situar a criança não meramente como um adulto em potencial sendo importante a reconstrução do significado e das práticas escolares de tal forma que se valorize a constituição do ser social e neste sentido que se entenda que aprendizagem e desenvolvimento dialogam constantemente. 
Sob outra ótica, Vesentini (2008, p.20), retrata a necessidade de

[...] elevar a escolaridade da população em geral e não somente de uma elite". Destarte para o autor a referida escolaridade urge romper com o tecnicismo típico do fordismo partindo afinal para uma leitura "construtivista, no sentido de levar as pessoas a pensar por conta própria, aprendendo a enfrentar novos desafios, criando novas respostas em vez de somente repetir velhas fórmulas. (VESENTINI, 2008, p. 20).

Assim, quando analisamos o processo de aprendizagem contínua dos indivíduos de uma escola, sejam alunos ou professores, temos de dirigir nosso olhar também para a concepção de gestão adotada, o padrão de comunicação existente, bem como as respectivas tecnologias de Informação e Comunicação (TICs) disponíveis.

Este quadro liga-se às transformações econômicas, sociais, políticas e culturais pelas quais a sociedade brasileira passa sendo necessário perceber que isto requer um professor: "[...] capaz de exercer sua profissão em correspondência às novas realidades da sociedade, do conhecimento, do aluno, dos meios de comunicação e informação." (LIBÂNEO: 2004, p. 81).

A educação escolar pode contribuir para a ampliação da compreensão da realidade, na medida em que os conhecimentos adquiridos instrumentalizem culturalmente os alunos a se perceberem como sujeitos ativos nas lutas sociais.

É preciso assegurar a todas as crianças o máximo de desenvolvimento de suas potencialidades, tendo em vista auxiliá-las na superação das desvantagens decorrentes das condições socioeconômicas desfavoráveis.

Portanto, é justamente neste cenário bastante complexo que devemos compreender aquilo que Tavares (1993) analisa em termos de escolas comunitárias no Brasil, ou em outras palavras, escolas voltadas para atender um público que se caracteriza essencialmente por pertencer à classe trabalhadora.

De acordo com Tavares (1993), no campo educacional verifica-se a dura realidade da seletividade que pode ser expressa, por exemplo, pela falta de vagas ou mesmo na péssima distribuição de vagas em relação às salas de aula e bairros nos quais se localizam as famílias dos alunos em idade escolar.

Segundo Tavares (1993, p. 160), nas últimas décadas:

$\mathrm{Na}$ tentativa de questionar e romper com a seletividade crônica do sistema educacional brasileiro, as classes trabalhadoras vêm formulando diferentes estratégias, tentando pressionar o Estado para atendimento às suas 
demandas educativas, principalmente o seu direito de entrar e permanecer na escola, além de, obviamente, receberem da escola aquilo que o ideário liberal promete - acesso ao conhecimento historicamente acumulado e o reconhecimento social de sua condição de cidadania. (TAVARES, 1993, p. 160).

Na década de 1970 surge a sociedade da informação devido à revolução tecnológica, embora esse momento seja visto por alguns especialistas como momento de crise, podemos encarar como mudança/transformação.

Mas como pensar o cenário educacional e sua adequação aos modernos sistemas de comunicação em um processo no qual ainda perdura velhos dilemas e problemas estruturais do sistema de ensino?

Consideramos nesse caso, amparados em Pretto (1996), que a reflexão teórica sobre a inter-relação educação e comunicação é de fato essencial para pensar o quadro educacional sendo que se apreende uma dura realidade nas Universidades brasileiras.

Segundo o referido autor as Universidades estão distantes ainda do âmago destas discussões mais específicas, o que de fato é reflexo da política educacional adotada e que se fundamenta muito mais em ações dispersas e desarticuladas, por escolas, universidades, empresas e projetos em geral que versam sobre esta temática do que por ações conjuntas num ideal e busca de cultura comum e enriquecedora.

Lefebvre (1973), ao discutir a lógica da reprodução das relações de produção no contexto escolar aponta que ela - escola - já não aparece apenas como instrumento de cultura ou como "escola", com funções oficializadas de educação e instrução, sendo que esta, na realidade, prepara proletários, enquanto a universidade, dirigentes, tecnocratas e gestores da produção capitalista.

Como Maroneze e Lara (2011, p. 59) apontam em seu trabalho:

As mudanças que demarcaram o capitalismo contemporâneo nas últimas décadas do século XX têm apontado para uma perversa lógica da exclusão, num processo que ressignifica os espaços laborativos e de qualificação, desafiando, constantemente, 0 mundo do trabalho e impondo novas exigências aos mais variados setores sociais e atividades do trabalho, envolvidos direta e indiretamente na produção. (MARONEZE E LARA, 2011, p. 59).

Observamos nesse cenário que o desenvolvimento do capitalismo não se faz linearmente, através de uma escala evolucionista, mas no âmbito da "dialética do 
desenvolvimento histórico" que neste contexto, nos permite refletir sobre a expansão do capital e suas relações de dominação, exploração e concentração na economia destes países, tal como podemos averiguar mediante o exemplo do Brasil.

Neste sentido, segundo Harvey (1992), vivemos o domínio da acumulação flexível a qual se apoia na flexibilidade dos processos de trabalho, dos mercados de trabalho, dos padrões e produtos de consumo o que por sua vez reflete em maior volatilidade do mercado e aumento da competição, com impactos, inclusive e diretamente, no mundo da educação.

Como aponta Maroneze e Lara (2011, p.61):

\begin{abstract}
Inseridos nessa lógica estão os trabalhadores docentes, que foram requisitados a responder às novas demandas sociais, tidas como necessárias para a formação do novo perfil de trabalhador e para atender à complexidade das mudanças derivadas da reestruturação produtiva e das políticas neoliberais implementadas pelo Estado. (MARONEZE E LARA, 2011, p. 61).
\end{abstract}

Aliás, os referidos autores chamam atenção para o fato de que tanto no contexto internacional como também no cenário nacional temos assistido a intensas contradições em um sistema marcadamente antagônico que preconiza o capital.

Ou melhor, a ordem metabólica do capital (MÉSZÁROS: 2007), a qual se espalha pelo mundo da educação e atinge sumariamente os trabalhadores mediante relações capitalistas de produção.

É justamente nesse contexto que se faz importante estarmos atentos e buscar elementos da formação de professores no Brasil o que nos dará suporte a compreender as nuances do trabalho docente e os percalços, desafios e possibilidades deste profissional.

\title{
CONSIDERAÇÕES FINAIS
}

Devemos continuar a buscar avanços nas leis e projetos educacionais e propiciar um ambiente fomentador e enriquecedor às nossas crianças e adolescentes para que tenham condições de descobrir e participar ativamente no mundo que aí está e desta forma garantir educação de qualidade a todos, permanência na escola, excelência no aprendizado e condições melhores de trabalho ao conjunto dos profissionais envolvidos. 
Portanto é fundamental fazer valer nosso direito de cidadão e buscar garantir ao conjunto da sociedade e particularmente para crianças e adolescentes não apenas o acesso como a permanência na rede pública de ensino e, paralelamente, propiciar aos professores dignidade na profissão para romper com a falácia do falso aprendizado e passo-a-passo mudar a imagem da educação no país.

Há a necessidade de se enfrentar, com urgência, a questão educacional com a finalidade de melhorar o seu desempenho para obter resultados a médio e longo prazos e, ao mesmo tempo, equacionar uma política de formação profissional que aproxime a qualificação dos trabalhadores ao processo educativo formal, considerada uma das principais exigências do setor produtivo.

Somente assim poderemos garantir um futuro melhor e mais justo para a sociedade e construir a cidadania.

\section{REFERÊNCIAS}

BARBOSA, T.; AZEVEDO, J. R. N. A geografia do vir-a-ser e o método para uma geografia livre: propostas educacionais. Cosmos. Presidente Prudente, v.2, n.1, 2004.

BRASIL. Câmara dos Deputados. Projeto de Lei 1603/96. Institui o sistema nacional de educação profissional. Brasília: 1996.

BRASIL. Constituição (1988). Constituição da República Federativa do Brasil. Brasília: Casa de Publicação do Senado Federal, 2006.

BRASIL. Lei no 10.172, de 09 de janeiro de 2001. Aprova o Plano Nacional de Educação. Brasília, 2001.

BRASIL. Lei no 9394, de 20 de dezembro de 1996. Estabelece as diretrizes e bases da educação nacional. Brasília, 1996.

BRASIL. Secretaria de Educação Básica. Orientações curriculares para o ensino médio. Brasília: MEC/SEB, 2006.

BRASIL. Secretaria de Educação Fundamental. Parâmetros curriculares nacionais: geografia. Brasília: MEC/SEF, 1998.

BRASIL. Secretaria de Educação Fundamental. Parâmetros curriculares nacionais: terceiro e quarto ciclos do ensino fundamental - introdução aos parâmetros curriculares nacionais. Brasília: MEC/SEF, 1998.

CALLAI, H. C. A geografia e a escola: muda a geografia? muda o ensino? Terra Livre, São Paulo, n.16, 2001.

CAVALCANTI, L. de S. Geografia, escola e construção do conhecimento. Campinas: Papirus, 1998.

ESTEBAN, M. T. Jogos de encaixe: educar ou formatar desde a pré-escola? In: GARCIA, R. L. (Org.) Revisitando a pré-escola. São Paulo: Cortez, 1993. 
GARCIA, R. L. (Org.) Revisitando a pré-escola. São Paulo: Cortez, 1993.

GOMES, D. B. Caminhando com arte na pré-escola. In: GARCIA, R. L. (Org.) Revisitando a préescola. São Paulo: Cortez, 1993.

HARVEY, David. Condição pós-moderna: uma pesquisa sobre as origens da mudança cultural. São Paulo, 1992.

KRAMER, S. (Org.). Com a pré-escola nas mãos. São Paulo: Ática, 1995.

LEFÈBVRE, H. A re-produção das relações de produção. Porto: Escorpião, 1973.

LIBÂNEO, J. C. Organização e gestão da escola. Goiânia: Alternativa, 2004.

LINHARES, C. F. S. A questão do magistério na educação básica. Tec. Educ. Rio de Janeiro. v. 20 (101), 1991. p.48-53.

MARONEZE, L.F.; LARA, A. M. B. A precarização do trabalho docente no contexto da reorganização capitalista das mudanças na legislação educacional brasileira pós 1990. Germinal. Londrina, v.3. n.2, 2011. p.58-70.

MÉSZÁROS, I. O desafio e o fardo do tempo histórico: o socialismo no século XXI. São Paulo: Boitempo, 2007.

NIDELCOFF, M. T. Uma escola para o povo. São Paulo: Brasiliense, 1983.

OLIVEIRA, D. A. A reestruturação do trabalho docente: precarização e flexibilização. Educ. Sociedade. Campinas, v.25, n.89. p.1127-1144, 2004.

PRETTO, N. L. Uma escola sem/com futuro. Campinas: Papirus, 1996.

ROMANELI, O. de O. História da educação no Brasil. Rio de Janeiro: Petrópolis, 1980.

SÃO PAULO. São Paulo faz escola: edição especial da proposta curricular: geografia, ciências. São Paulo: 2008. (ENSINO FUNDAMENTAL).

SÃO PAULO. São Paulo faz escola: edição especial da proposta curricular: geografia, história, filosofia. São Paulo: 2008. (ENSINO MÉDIO).

TAVARES, M. T. G. Escolas comunitárias no Brasil: solução de um problema ou denúncia de uma história de omissão? In: GARCIA, R. L. (Org.) Revisitando a pré-escola. São Paulo: Cortez, 1993.

UNESCO. Educação: um tesouro a descobrir. São Paulo. Cortez, Brasília: MEC. Unesco, 1999.

VESENTINI, J. W. Educação e ensino de geografia: instrumentos de dominação e/ou de libertação. In.: CARLOS, A. F. A (Org.). A geografia na sala de aula. São Paulo: Contexto, 2008. 